\title{
ESTUDO E OBSERVAÇÃO DO COMPORTAMENTO DE MAES E GESTANTES, EM RELAÇÃO AOS CUIDADOS QUE DISPENSAM OU DISPENSARAO A SEUS FILHOS
}

\author{
Daisy Leslie Steagall Gomes *
}

$I-I N T R O D U C ̧ \tilde{A} O$

O trabalho da enfermeira de Saúde Pública sofre influências das condições sócio-economico-sanitárias da comunidade em que trabalha; no entanto, são seus objetivos:

1 - Prestar cuidados de enfermagem necessários à prevenção das doenças e ao fomento da saúde.

2 - Prestar cuidados de enfermagem a indivíduos, grupos e comunidades visando:
a) a seu bem-estar físico, mental e social,
b) ao tratamento de suas enfermidades,
c) à reabilitação dos comprometidos.

Neste campo vasto da saúde, a higiene materna e da criança continuam sendo uma das mais importantes atividades, com alta priorldade em nosso país, exigindo dos profissionais de saúde, zelo constante nos trabalhos que se desenvolvem nesta área.

Dizem os peritos da O.M.S. ${ }^{* *}$ em assuntos de higiene maternoinfantil que: "Cada criança, sempre que possível, deve viver e crescer num ambiente saudável, carinhoso e seguro, recebendo alimen-

* Professor-colaborador da disciplina Enfermagem de Saúde Pública do Departamento de Enfermagem Geral e Especializada da Escola de Enfermagem de Ribeirão Preto da U.S.P.

* O.M.S. - Organização Mundial de Saúde. 
tação apropriada, supervisão sanitária e eficiente assistência méđiica, com ensinamentos e educação sanitária (9)". Para que tal recomendação seja atendida é necessário que se dê a importância devida, aos trabalhos de saúde pública, que se desenvolvem junto à família, por ser esta o elemento consolidador na formação de hábitos, atitudes e conhecimentos dos indivíduos que formarão a sociedade futura. Inicia-se este trabalho em nosso contacto com a gestante durante o pré-natal, quando ela terá de ser educada, não só quanto ao preparo para o parto, como nos cuidados a serem dispensados ao recém-nascido, exposto aos riscos e agravos do meio smbiente, tanto mais comprometedores, quanto forem carentes as condições (sócio-econômico-educacional-sanitárias) da família.

O serviço de enfermagem deve aproveitar a oportunidade de educar grávidas e puérperas nos ambulatórios, hospitais, materniaades e nos contactos domiciliares para que certas técnicas recomendáveis, como: amamentação, cuidados higiênicos cuidados com coto umbilical, imunizações, possam ser aprendidas. Assim, na volta ao ambiente doméstico, elas poderão pelo menos, amenizar os riscos a que estão expostos os recém-nascidos, pelas condições que os cercam.

"A assistência pré-natal tem sido mencionada como um dos fatores responsáveis pela diminuição das taxas de mortalidade materna (11)" e a enfermeira não pode desatender aos imperativos da verificação do meio ambiente, aproveitando a oportunidade de educar, orientar e demonstrar, quais as melhores condutas no cuidado e proteção do recém-nascido. Lembrar ainda que a base segura para c crescimento e desenvolvimento da criança depende da "adequada alimentação" e que a amamentação deve ser destacada para se evitar o desmame precoce de seu filho. Ressalte-se que proteger as crianças mediante imunizações é fator de suma importância, devido ao grande número de doenças transmissíveis, que têm mantido os coeficientes de morbidade e mortalidade em nossos meios principalmente em áreas onde condições do meio ambiente associados a cutros fatores (econômico-social e educacional) constituem sérias ameaças. Por último, mas não menos importante, considerar que o tétano e as doenças infecciosas, juntamente com as parasitárias representam taxas elevadas de óbitos ocorridos em menores de 1 ano, no Estado de São Paulo, o que já diz da necessidade das mães aprenderem do coto e cicatriz umbilical, para que incorporem novos hábitos e se libertem da influência da medicina popular que, segundo Piovesan "desempenha ainda papel importante nas populações rurais da cultura brasileira, sendo o comportamento. em saúde fortemente influenciado por crendices e tabus"(5). 
Parece-nos que a equipe de saúde tem-se lembrado dessas situações e necessidades, reconhecendo que a educação em saúde é básica; no entanto, é preciso avaliar o que temos feito.

"A avaliação é o termômetro do administrador para conduzir com segurança o trabalho programado. Ela que justifica a manutenção das atividades e dos métodos em andamento, impondo a modificacão parcial ou total do esquema traçado"(6).

Esta preocupação em avaliar e atualizar programas de saúde tem levado os profissionais, deste campo, a reformulação constantes, na forma de abordagem e na aplicação de medidas de saúde. Isto se impõe, uma vez que é intenção dessa equipe a "educação e o ensino" de modo a permitir ao indivíduo, família, grupos e à própria comunidade, aquisição de conhecimentos, habilidades intelectuais e motoras atitudes aplicáveis tanto nas situações rotineiras quanto nas novas que surjam. $\mathrm{E}$ uma das responsabilidade da equipe de enfermagem preparar a comunidade para problemas novos e situaçōes imprevistas, procurando dar os conhecimentos, que na época se mostram mais úteis, permitindo assim enfrentar com certa independência e reflexão as situações que surjam.

As mudanças em nossa cultura têm sido rápidas e constantes, é quase impossível prever as que surgirão no amanhã e com elas os problemas e necessidades.

Em face desta' situação, propomo-nos a avaliar qual tem sido a influência da enfermagem, em seu papel de educadora, junto a gestantes e mães. Esta avaliação a que nos propomos servirá como um meio, um instrumento auxiliar de nossos trabalhos futuros, no campo da saúde pública.

\section{II - OBJETIVOS}

Avaliar os efeitos das atividades educativas da enfermagem*, na orientação de mães e gestantes, no cuidado a seus filhos.

\section{III - POPULAÇÃOO}

Foram incluídas no trabalho: a) Gestantes em qualquer mês da gravidez que procuraram o ambulatório para o pré-natal, durante a semana de observações. As condições de estado civil, econômica, social, educacional, cor, residência não serão consideradas; b) Mães, que compareceram durante a semana de observaçōes, ao ambulatório de pediatria, para trazerem seus filhos ao seguimento da puericultura.

* Enfermagem - Incluem-se aqui. todos os elementos que fazem parte da equipe de enfermagem: atendentes, auxiliares e enfermeiros e estudantes de enfermagem que estagiam neste Hospital-Escola: 
Não serão consideradas as situações social, econômica, educacional, cor, residência e sexo.

O período de idade considerado para as crianças foi estipulado de 0 (zero) a 12 (doze) meses.

\section{IV - MATERIAL E METODO}

Para avaliarmos a influência educativa da enfermagem junto à mãe e gestantes, escolhemos para campo de trabalho o Ambulatório do Hospital das Clínicas da FMRP-USP nas especialidades Obstetrícia e Pediatria.

Nossas observações foram feitas com todas as gestantes e mães que compareceram a esses ambulatórios, no período de uma semana, compreendido de segunda a sexta-feira.

Propusemo-nos também, ao mesmo tempo, usar um questionário (anexo I e II) já em segundo teste, por se constituir este, a base das informações obtidas.

Assim nossa coleta de dados se fez através de questionário, entrevistas e observações.

Para aplicação do material, selecionamos duas enfermeiras, que - antes participaram de uma apresentação e discussão do trabalho a ser realizado e durante 3 (três) dias fizeram experimentalmente um treinamento para que a aplicação fosse padronizada.

Essas duas enfermeiras (uma da Pediatria e uma da Obstetrícia) já faziam atendimento nos dois ambulatórios, o que facilitou a aplicação do material.

As razões de termos escolhido estes ambulatórios são:

1 - Os ambulatórios de Obstetrícia e Pediatria constituem campo de nossas atividades.

2 - Temos facilidade de acesso.

3 - Já existe uma rotina organizada de atendimento.

4 - Possibilita o nosso seguimento.

5 - Nossa presença no ambulatório é constante. 
Informaçōes sobre o atendimento de primigestas e multigestas do ambulatório de obstetricia do Hospital das Clinicas da Faculdade de Medicina de Ribeirão Preto.

ATIVIDADES

PRIMIGESTAS
Gestantes atendidas por dia de consulta

Número de casos novos por semana

Número de retornos na semana Período de gravidez em que mais aparecem

Período entre uma consulta e retorno

Frequência de retorno

Das atendidas, quantas residem em Ribeirão Preto

\begin{tabular}{cc}
4 & 5 \\
10 & 10 a 15 \\
10 & \multicolumn{1}{c}{-} \\
$4 .^{\circ}$ mês & \multicolumn{2}{c}{30 a 45 dias } \\
$50 \%$ dias & $\begin{array}{l}\text { Frequência con- } \\
\text { siderada "boa" } \\
\text { (sic). Não há } \\
\text { dados. }\end{array}$
\end{tabular}

De 46 atendidas

24 são de Ribei- Não há dados. rão Preto

Os dados referentes às multigestas não são completos, por não ter sido ainda reorganizado o atendimento de enfermagem, o que já foi feito com as primigestas.

As pacientes passam pelos exames médicos, fazem os exames c.e laboratório e de rotina no próprio Hospital. São seguidas no Ambulatório até a época do parto, e este é feito também no Hospital.

\section{$V-R E S U L T A D O S$}

Durante a semana de observaçōes, foram entrevistadas quarenta e duas (42) gestantes, sendo vinte (20) primigestas e vinte e duas (22) multigestas, com idade entre dezesseis (16) e trinta e seis (36) anos. A maior parte entre o terceiro (3.') e sexto mês de gravidez.

Das quarenta e duas gestantes, apenas vinte e duas (22), isto é, $52,00 \%$, residiam na cidade de Ribeirão Preto, enquanto as demais 
residiam fora, sendo que a maior parte delas, isto é $54,76 \%$ procuraram o médico para a primeira consulta de pré-natal entre o terceiro e o sexto mês de gravidez.

As respostas que obtivemos, classificamos em comportamentos: positivos, negativos e neutros, com a frequência expressa em porcentagem, para ressaltar melhor os resultados e facilitar a discussão.

Considerou-se como comportamento positivo aqueles que são os desejados e estão de acordo com as orientações de saúde; comportamento negativo os não desejados e que contrariam orientações de saúde e comportamento neutro os que não se definiram em nenhuma posição.

Foram feitas observações e entrevistas para vinte (20) mães, que compareceram durante aquela semana, para trazerem seus filhos à consulta de puericultura. Para estas, foram aplicados os questionários e a criança sofreu observação direta da enfermeira a fim de que se vissem e anotassem as condições de vestuário, cicatriz umbilical e a higiene da mesma.

As crianças tinham de dez (10) a trezentos e sessenta (360) dias, portanto todas já com a queda do coto umbilical.

\section{DISCUSSÃO}

Nossa proposição em avaliar qual tem sido a influência da enfermagem, educando gestantes e mães, levou-nos a executar este trabalho num ambulatório, onde rotineiramente é feita orientação a mães e gestantes, sob forma de aulas expositivas ou grupos de discussão, antes das consultas, e individual, após consulta.

As respostas das gestańtes mostraram que os comportamentos positivos foram em número maior que os negativos, numa proporção de 12 (doze positivos para \& (quatro) negativos.

Se por um lado observarmos que $59,78 \%$ delas têm noção da forma correta de vestir seus filhos de acordo com o clima, por oútro, o uso da touca e da faixa larga ainda persiste em percentagem negativa maior, embora entre as que não aceitam o uso da faixa, alguns tenham lembrado que foi esta a orientação recebida no hospital.

O cuidado com a cicatriz umbilical na maioria $(64,00 \%)$ indicou cuidado certo, no entanto encontramos $19,04 \%$ de gestantes que disseram que usariam óleo e fumo.

Quanto à imunização, as gestantes numa frequência de $\mathbf{7 1 , 4 0 \%}$ disseram que conheciam as razōes de se vacinar uma criança e quais os locais onde poderiam ser procuradas essas vacinas. Embora tenha aparecido a resposta de uma gestante que "esperaria pela unidade volante para vacinar", sabemos que estas unidades só saem €m campo $\mathrm{\epsilon m}$ ocasiōes de campanhas, e $25,75 \%$ disseram não saber 
para que serve uma vacina, o que nos informa que a divulgação das campanhas e a orientação sobre vacina não sensibilizaram este grupo.

Chamou-nos atenção a forma como nos responderam sobre a escolha de um leite bom para dar à criança, pois se 11 (onze) que correspondem a $25,75 \%$ afirmaram ser o leite materno bom, uma outra fração $19,04 \%$ disse ser o leite de vaca melhor, enquanto que a metade, ou seja $52,38 \%$ escolheram leite em pó. Notese que este ensino não foi feito no ambiente do hospital mas sim o "terem ouvido falar serem eles bons para criança". Isto nos chama atenção ao compararmos com o parágrafo anterior. Sera a forma comercial de comunicação e de apresentação de produto que é feita corretamente?

Parece-nos que a propaganda que penetra os lares, levando o nome de seus produtos (e o seu consequente consumo), leva as mães a deixarem de dar o peito e o leite de vaca fresco para darem o leite em pó.

A maioria das gestantes sabe quais são os intervalos entre as mamadas, como devem ser, conhecem o melhor frasco para mamadeira e entendem que a diluição do leite é bom para a criança; no entanto 23 (vinte e três), isto é, $55,00 \%$ adicionariam maizena, araruta, farinha de arroz e de trigo à mamadeira.

Dar suco à criança, segundo $71,43 \%$ fará bem, mas para $21,43 \%$ a criança de três meses é nova para tomar suco"; enquanto 6,14\% não sabiam.

Pareceu não existir dúvida quanto à administração de água várias vezes ao dia, pois $97,61 \%$ afirmaram que isto fará bem à criança.

Os resultados evidenciam que há poucas dúvidas e comportamentos negativos no que diz respeito ao banho diário, à lavagem de cabeça e à própria mãe ser capaz de dar banho no filho.

A conduta de se pedir a ajuda de uma pessoa mais velha e também à mais próxima, para cuidar da criança numa hora de "necessiciade", ficou evidenciado, quando elas nos responderam que recorreriam ao médico e enfermeira somente $19,05 \%$; enquanto que $30,90 \%$ pediram ajuda à mãe e $\mathbf{2 3 , 0 0 \%}$ pediram à sogra. As demais, em porcentagens bem menores, a vizinhos e outros parentes. Isto tem base, segundo elas porque "essas pessoas têm maior experiência".

Um grupo de $42,86 \%$ de gestantes, que foram classificadas como tendo comportamento positivo quanto ao uso da touca, dessas $25,00 \%$ disseram que receberam orientação no hospital.

Descreve-se a seguir o comportamento das mães em relação aos cuidados dispensados a seus filhos. 
O vestuário das crianças estava de acordo com o dia, mas $45,00 \%$, nove (9) mães, preferiram usar toucas nas crianças na hora de dormir e de passear. Essa mesma porcentagem indicou o uso da faixa larga "para dormir", "para carregar", "somente à noite", enquanto cluas disseram usar o dia todo.

Na cicatriz umbilical $30,00 \%$ disseram ter usado óleo, sulfa e talco; 50,00\% usaram mertiolate, éter, mercúrio-cromo e sulfa; e $20,00 \%$ nada usaram.

Inquiridas sobre a imunização das crianças, vimos que 9 (nove) estavam abaixo da idade e que das 11 (onze) restantes, 2 (duas), isto é, $17,27 \%$ não haviam iniciado, enquanto que $99,08 \%$ já tinham iniciado esquema, algumas já com reforço.

A alimentação dessas crianças $55,00 \%$ é natural, $40,00 \%$ é artificial e $5,00 \%$ é mista.

Observou-se que elas estão seguindo a orientação certa quanto ao tipo de aleitamento, porém o horário em $55,00 \%$ delas está sendo feito de forma aleatória, isto é, "sempre que a criança chora" ou até de duas em duas horas.

O preparo da mamadeira em $33,33 \%$ dos casos está sendo feito de forma inadequada*.

Das crianças em idade de receber os sucos, $75,00 \%$ já estavam recebendo enquanto $25,00 \%$ não tomavam ainda.

Quanto à aperência pessoal, foi observado que as crianças $(90,00 \%)$ estavam limpas, e segundo as informaçōes das mães, elas tomavam banho diariamente $(\mathbf{7 5}, 00 \%)$ e lavavam a cabeça das mesmas, todos os dias $(60,00 \%)$. Entretanto, algumas mães disseram que não lavam a cabeça da criança quando elas estão doentes.

Observamos que do total de respostas obtidas das mães 13 (treze) foram considerados positivos e para 2 (dois) considerados negativos.

Comparando as respostas obtidas entre um grupo de mulherers que se prepararam para o parto e para cuidar do filho e um outro de mulheres que já tiveram seu parto e já têm seus filhos, nós observamos que, quanto ao vestuário da criança, existe uma certa correspondência entre o "que farei quando meu filho nascer" (gestantes) e o "que faço com meu filho" (mães). Entretanto dizem algumas gestantes que usarão no umbigo de seus filhos fumo e óleo, o que não fizeram as mães, segundo suas declarações.

Dizem-nos $71,40 \%$ das gestantes que há razões para se vacinar crianças enquanto que as mães somente $45,00 \%$ dizem que vacinaram seus filhos.

* Forma inadequada - a proporção de leite e agua não corresponde ao prescrito. 
No grupo de gestantes apenas $25,75 \%$ afirmaram que o leite materno é bom e achamos entre mães $55,00 \%$ amamentando seus filhos somente no peito.

Gestantes afirmaram, num total de $71,40 \%$, que sabem qual o intervalo certo de dar alimento para a criança e a forma correta de prepará-lo, enquanto que nas mães encontramos a maior porcentagem para o lado do comportamento negativo quanto ao horário, e, quanto ao preparo, 33,33\% estavam fazendo inadequadamente.

Se por um lado, $55,00 \%$ de gestantes nos dizem que acrescentariam farinhas na mamadeira, $100 \%$ das mães dizem que nada acrescentam fora da prescrição médica.

Há concordância, quando dizem as gestantes $(92,80 \%)$ que 0 banho deve ser diário com o que as mães afirmam $(90,00 \%)$ que o fazem diariamente, o mesmo ocorrendo com a lavagem diária da cabeça da criança, dizendo as gestantes num total de $71,40 \%$ que assim fariam, enquanto as mães, em porcentagem menor, 60,00\% dizem assim fazer.

Encontramos em 8 (oito) situações, gestantes respondendo "não sei", enquanto que mães em apena $\mathrm{s}(4)$ se mostraram com dúvida.

Pareceu-nos que a expectativa do parto funcionava na gestante como "motivação" para querer saber "como cuidar" do seu próximo filho, enquanto as mães se mostram também intressadas, contudo restritas às necessidades que estão vivendo no momento, como processo de ajuda para resolver uma situação imediata.

No entanto, há dificuldades evidentes em se saber se realmente c comportamento existe. Por exemplo, se nos foi fácil dizer, após examinar a roupa e o corpo das crianças, se estas estavam limpas ou não. Não nos é igualmente fácil garantir, que as mães que disseram "dar banho diariamente na criança" traduziam uma situação real, pois para isto precisaríamos estar no domicílio para observação. A afirmação das mães e o fato de as crianças se apresentarem, no momento, limpas e adequadamente vestidas, ainda não excluem a possibilidade daquele comportamento só para o dia da consulta.

Tornou-se resposta fácil saber se a criança está imunizada e por quais vacinas mediante a apresentação dos documentos de vacinas (cartōes e os registros feitos na pasta do paciente.

As respostas evidenciam que as gestantes, em sua maioria, sabem "como deverá ser feito" e que a maior parte das mães "fazem o prescrito", contudo, o que não nos fica evidenciado é se "farão" ou "fazem" no cotidiano o que lhes foi ensinado e orientado.

Como educação envolve "mudança de comportamento, é razoável pensar que o grupo mais acessível a ela, nos parece, seriam as mães e gestantes que responderam "não sei" (comportamento neutro). Por outro lado, aquelas de "comportamento positivo" que gos- 
tariamos que assim continuassem a fazer, temos que atendê-las em matéria de educação, para que o "reforço" garanta a permanência do comportamento. Resta-nos considerar o grupo de comportamento negativo que nos parece o mais difícil e penoso, por já ter incorporado uma forma não desejada; no entanto, parece-nos que ainda compensa, em termos econômicos e de saúde, a tentativa de "mudança de comportamento".

No que pesem nossas consideraçōes, devemos ressaltar que o grupo de gestantes deixou transparecer maior interesse. Talvez seja esta a fase melhor para a execução deste tipo de programa.

\section{$V I I-C O N C L U S O E E S$}

Observando e estudando o material obtido entre um grupo de gestantes e de mães que frequentam o ambulatório do HC da FMRPUSP, buscando o seu atendimento no Pré-Natal e o de seus filhos na Pediatria (Puericultura), observamos que:

1 - Somente o grupo de gestantes evidenciou ter um comportamento aprendido com a pessoal da equipe de saúde.

2 - Em algumas situações de cuidado com a criança, houve certa concordância entre o "que farei" (gestante) e o "que faço" (mãe) .

3 - Os pontos em que houve divergência e que mais nos chamaram atenção foram: o cuidado com a cicatriz umbilical, imunização e amamentação natural.

4 - Alguns comportamentos foram fáceis de avaliar por serem verificados no momento (vestuário, e higiene da criança), enquanto outros, como "dar banho e lavar a cabeça diariamente", foram considerados pela resposta da mãe.

5 - As gestantes e mães evidenciam em algumas situações que "sabem como fazer", no entanto, por vezes, não o fazem.

6 - A ação educativa da enfermagem não foi destacada em rienhuma resposta, entretanto, alguns comportamentos de mães e respostas de gestantes mostraram que elas "lembram" e "fazem" como são ensinadas por estas.

7 - Algumas gestantes se mostravam mais interessadas na entrevista e no contacto com a enfermeira que as mães, sugerindo que $n$ estado de gestação as motivam a aprender como cuidar de seus filhos. As gestantes seriam as mais sensíveis a programas de educação em saúde. 
8 - O questionário por nós elaborado, embora com falhas que dificultaram a obtenção de respostas, obrigando-nos, às vezes, a fazer anotaçōes à margem, serviu como meio de levantamento.

9 - Os dados obtidos nos trouxeram informaçōes sobre a população com que trabalharemos, permitindo-nos uma sondagem acerca de assuntos que deveremos incluir em cursos para mães e gestantes.

10 - Embora se possam fazer algumas consideraçōes, sobre qual grupo, quanto ao tipo de comportamento, é o melhor para se tentar mudanças, achamos razoável, sob o aspecto econômico e de saúde, trabalhar com os 3 .

\section{VIII - RECOMENDAÇŌES}

Considerando que, avaliar a atividade educativa da enfermagem de saúde pública:

- é de grande importância para a enfermagem, por estar relacionado com um aspecto de seu campo prático de trabalho, e referir-se à situação real que enfrentamos;

- é problema interessante, que nos conduzirá a novos campos de estudo e trabalho;

- que tal trabalho é factível com a competência da enfermeira, desde que haja tempo e material suficiente para isto.

Recomendamos que seria compensador continuar o trabalho, desta feita melhorando o questionário, selecionando um grupo só de gestantes, ensinando-as no cuidado a seus filhos, fazendo depois - seguimento e observando o seu comportamento nestes cuidados, para que assim obtivéssemos com mais clareza e através de um ensino sistematizado a resposta do "trabalho educativo da enfermeira" e posteriormente procurar saber qual o melhor "método para esse ensino sistematizado".

\section{ANEXO I}

ROTEIRO PARA ENTREVISTAS COM GESTANTES

Início da entrevista ......... horas.

Reg. n. ${ }^{o} \ldots \ldots \ldots$ Idade $\ldots \ldots$ me mês de gravidez $\ldots \ldots \ldots \ldots \ldots$

Residência - em Ribeirão Preto fora de Ribeirão Preto Primigesta Multigesta

1. ${ }^{\mathrm{a}}$ visita do médico com $\ldots \ldots$ meses de gestação. 
$I$ - APARENCIA PESSOAL

1 - Se a senhora estivesse com seu filhinho agora em seu colo com quais destas peças ele estaria vestido?

$\operatorname{sim} \quad$ não

$\begin{array}{lll}\text { camisinha } & - & - \\ \text { fralda } & - & - \\ \text { touca } & - & - \\ \text { cueiro de flanela } & - & - \\ \text { sapato de lã } & - & - \\ \text { cobertorzinho } & - & -\end{array}$

(A paciente só dirá sim ou não a cada peça enumerada)

2 - Em quais horas a senhora usaria touca em seu nenê?

$\begin{array}{lll} & \text { sim } & \text { não } \\ \text { o dia inteiro } & - & - \\ \text { para dormir } & - & - \\ \text { não usaria } & - & - \\ \text { para passear } & - & -\end{array}$

3 - A senhora usaria a faixa larga?

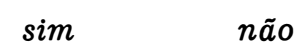

Por que?

$I I-C I C A T R I Z$ UMBILICAL

1 - Se o umbigo do nenê já houvesse caído a senhora colocaria no local:

$$
\text { sim não }
$$

$\begin{array}{lll}\text { éter } & - & - \\ \text { álcool } & - & - \\ \text { óleo } & - & - \\ \text { borra de café } & - & - \\ \text { fumo } & - & - \\ \text { nada } & - & -\end{array}$


$I I I-I M U N I Z A C ̧ \bar{A} O$

Atenção - Nestas perguntas não leia as alternativas. Apenas assinale a resposta dada pelo paciente.

1 - Se a senhora vacinasse seu filho a vacina serviria para ele ficar

(aguardar a resposta e classificar)

$$
\text { sim não }
$$

mais gordo

protegido contra

doenças

não aconteceria nada - -

outras

não sabe

2 - Se a senhora quisesse vacinar seu filho, a senhora o levaria a qualquer lugar? (não leia as respostas)

farmácia

Posto de Puericultura

Hospital das Clínicas

Centro de Saúde

outros locais

\section{IV - ALIMENTAÇĀO}

1 - Se a senhora tivesse que escolher um leite bom para seu filho, a senhora escolheria (não leia as alternativas. Apenas classifique).

vaca
materno
leite em pó
Outros $\ldots \ldots \ldots \ldots \ldots \ldots \ldots \ldots$

2 - Se seu filho tivesse sete dias qual o horário que a senhora acha que seria melhor para ele mamar? (não leia, apenas classifique).

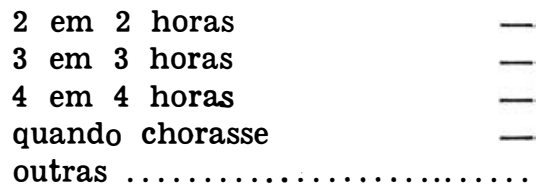


3 - Se a senhora tivesse que escolher uma mamadeira para seu filho a senhora escolheria (não leia, apenas classifique).

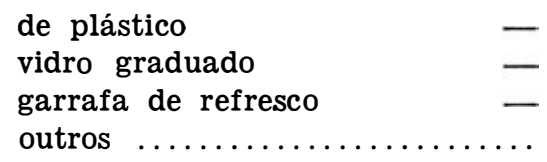

Nota: As que se seguem ler as alternativas, e assinalá-las.

4 - Se seu médico lhe dissesse para dar a seu filho a seguinte mamadeira: $50 \mathrm{~g}$. de leite $+50 \mathrm{~g}$. de água + uma colher de açúcar, a senhora acharia que:

a mamadeira ficará fraca -

a criança ficará com fome -

a mamadeira estará boa

para o nenê

5 - Se a senhora tivesse de dar só leite de vaca para seu nenê, o que a senhora acrescentaria?

$\begin{array}{ll}\text { araruta } & - \\ \text { maizena } & - \\ \text { farinha de trigo } & - \\ \text { nenhum destes } & -\end{array}$

6 -- Se a senhora tivesse de dar suco de tomate ou de laranja para seu filho de 3 meses a senhora acharia que:

faria bem a criança
a criança não precisa
a criança é nova para tomar -
suco

7 - Se recomendarem à senhora dar um pouco de água para sua criança várias vezes ao dia, a senhora acha que:

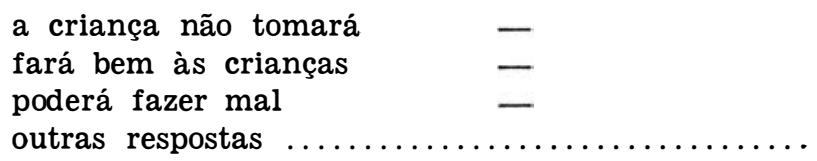




\section{I' - APARENCIA PESSOAL}

1 - A senhora acha que a criança deve tomar banho

todos os dias

um dia sim outro não

toda vez que for necessário

outras respostas

2 - O que a senhora acha de darmos banho diariamente numa criança de um mês:

é bobagem

enfraquecerá a criança

será bom para ela

3 - Quando a senhora lavaria a cabeça do nenê?

quando estivesse suja
todos os dias
uma vez por semana

4 - A senhora seria capaz de dar banho no seu filho quando ele estivesse com quatro dias?

$\begin{array}{ll}\text { sim } & - \\ \text { não } & - \\ \text { outra } & -\end{array}$

5 - Caso a senhora necessitasse de uma ajuda para cuidar do seu nenê, quem chamaria?

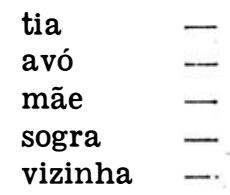

Entrevistado por:

Término da entrevista ......... horas.

Tempo gasto:

Data: .............. 


\author{
ANEXO II \\ ROTEIRO PARA ENTREVISTAS COM MÃES \\ Início da entrevista .......... horas.
}

Keg. n. ${ }^{\circ} \ldots \ldots \ldots$ Idade

$$
\begin{aligned}
& \text { Residência - Em Ribeirão Preto } \\
& \text { Fora de Ribeirão Preto - }
\end{aligned}
$$

I - VESTUÁRIO

1 - O vestuário da criança está adequado ao dia?

$$
\begin{aligned}
& \text { sim } \\
& \text { não }
\end{aligned}
$$

2 - A criança usa touca?

$$
\begin{array}{ll}
\operatorname{sim} \quad-\quad & \text { à noite } \\
& \text { para passear } \\
& 0 \text { dia todo }
\end{array}
$$

não -

3 - A criança usa faixa larga:

$$
\begin{aligned}
& \text { sim - } \quad \begin{array}{l}
\text { para ser carregada } \\
\text { o dia todo }
\end{array} \\
& \text { não }-
\end{aligned}
$$

\title{
$I I-C I C A T R I Z$ UMBILICAL
}

1 - O que a mãe gosta de usar na cicatriz umbilical?

$$
\begin{aligned}
& \begin{array}{l}
\text { éter } \\
\text { benzina } \\
\text { álcool } \\
\text { mertiolate } \\
\text { fumo } \\
\text { borra de café }
\end{array} \\
& \text { outros (especificar) } \quad \ldots \ldots \ldots \ldots \ldots \ldots \ldots \ldots
\end{aligned}
$$


III - APARENCIA PESSOAL

1 - A criança está limpa

$$
\begin{aligned}
& \text { sim }- \\
& \text { não - }
\end{aligned}
$$

2 - Quantas vezes a criança toma banho?

$$
\begin{array}{lll}
1 \text { vez ao dia } & - \\
2 \text { vezes por semana } & - \\
3 \text { vezes por semana } & - \\
4 \text { vezes por semana } & - \\
1 \text { vez por semana } & - \\
\text { quando necessário } & -
\end{array}
$$

\begin{tabular}{|c|c|}
\hline mãe & - \\
\hline avó & - \\
\hline tia & - \\
\hline $\begin{array}{l}\text { irmã } \\
\text { vizinha }\end{array}$ & \\
\hline
\end{tabular}

3 - Quantas vezes lava a cabeça?

\begin{tabular}{|c|c|c|c|c|c|}
\hline \multirow{2}{*}{$\begin{array}{l}\text { BCG } \\
\text { Tríplice }\end{array}$} & - & - & & & Data \\
\hline & - & - & $1 .^{a}$ & - & $\ldots \ldots \ldots \ldots \ldots \ldots$ \\
\hline & & & 2. ${ }^{a}$ & - & ..... \\
\hline & & & $3 .^{a}$ & - & \\
\hline & & & Ref. & - & \\
\hline
\end{tabular}

$$
\begin{array}{lll}
1 & \text { vez por semana } & - \\
2 & \text { vezes por semana } & - \\
3 & \text { vizes por semana } & - \\
4 & \text { vezes por semana } & - \\
1 & \text { vez ao dia } & -
\end{array}
$$

4 - Quem dá banho na criança?

\section{IV - IMUNIZAÇÃO}

1 - A criança já tomou vacina?

$\begin{array}{ll}\text { Anti-variólica } & - \\ \text { BCG } & - \\ \text { Tríplice } & - \\ \text { Sabin } & - \\ \text { Sarampo } & -\end{array}$

2 - Assinalar as doses das vacinas 
3 - Onde foi feita a vacina?

Hospital das Clínicas Sim - Não -

Posto de Puericultura Sim - Não -

Farmácia Sim - Não -

Outros locais

(especificar)

$V-A L I M E N T A C ̧ A \bar{O}$

1 - O aleitamento atual da criança é

$\begin{array}{ll}\text { natural } & - \\ \text { artificial } & - \\ \text { misto } & -\end{array}$

2 - Se natural ,a criança mama:

de $3 / 3 \mathrm{~h}$

de $4 / 4 \quad h$

sempre que chora -

de $2 / 2 \quad h$

3 - Se artificial, a mamadeira é:

graduada

vidro de refresco

plástico

vidro comum

4 - Os utensílios usados no preparo das mamadeiras são:

só para a criança

qualquer um

de uso comum para -

todos de casa

5 - A preparação do leite e água está:

adequada

inadequada

6 - Se mista, como ela é feita:

1.a hora de mamada

no peito

2. ${ }^{\text {a }}$ hora de mamada

e mamadeira

ou

na mesma hora peito

em seguida mamadeira - 
7 - Na mamadeira a mãe coloca:

araruta

maizena

farinha de trigo

nenhum desses

8 - A criança toma suco?

tomate

limão

laranja

misto

não toma suco

Final da Entrevista

T'empo Gasto:

horas

Entrevistadora:

\section{BIBLIOGRAFIA}

1 - CAUSES and prevention of perinatal mortality. WHO Chronicle, 21 (2): 43-49, Feb. 1967.

2 - EHRESMAN, E. - Cuidados de enfermeria a la madre y al niño. B. Of. Sanit, Panamer, 64 (4): 322-327, abr. 1968.

3 - LOZIER, H. \& BAEZA, O. - La evaluacíon en educación con referencia a la higiene maternal y del ambiente. B. Of. Sanit. Panamer. 31 (6): 565-577, des. 1951.

4 - MARIA DO CRISTO REDENTOR, Irmã - O pré-natal como ponto de partida para uma assistência integral à família. $R$. Bras. Enfermagem, 17 (5): 295-306, out. 1964.

5 - PIOVESAN, A. Antropologia. São Paulo, Cadeira de Técnica de Saúde Pública, Faculdade Saúde Pública. Universidade de São Paulo, 1959 (mimeografado).

6 - RODRIGUES, B. A. - Saúde Pública e desenvolvimento nacional. In: Fundamentos de Administração Sanitária. Rio de Janeiro, Edit. Freitas Bastos, 1967. pág. 31 a 76.

7 - SÃO PAULO. Secretaria de Saúde Pública - Normas para o programa de vacinação, São Paulo, 1968.

8 - SEMINARIO sobre assistência materno-infantil no Brasil, Rio de Janeiro, 20-29 set. 1965 - Aspectos de serviço e educaçāo em enfermagem $e$ obstetricia (mimeografado).

9 - WORLD HEALTH ORGANIZATION. Comité de expertos en Higiene Materno-infantil - Administración de los servicios de higiene e maternoinfantil; segundo informe. Ginebra, OMS, 1957. (Serie de informes técnicos, n. ${ }^{\circ} 115$ ). 
10 - WORLD HEALTH ORGANIZATION. Expert Comittee on maternity care. First report; a preliminary survey. Geneva, WHO, 1952 (Tecnical Report Series, n. ${ }^{\circ}$ 51).

11 - WORLD HEALTH ORGANIZATION. Comité de expertos de la OMS sobre la función de la partera en la asistencia a la madre. - Informe. Ginebra, OMS, 1966 (Serie de Informes Tecnicos, n. ${ }^{\circ} 331$ ).

12 - YANKAUER, A. - Planificacíon nacional y estabelecimiento de normas de higiene maternoinfantil in America Latina. $B$. Of. Sanit Panamer. 60 (6): 496-509. jun. 1966. 